\title{
Study of the Effect of Mineral Components on the Permeability Impairment Rate and Stress Sensitivity Factor of Shale
}

\author{
Shuang Wang $\mathbb{D}^{1,2}$ Zhonghu Wu $\mathbb{D}^{3},{ }^{3}$ Jun Chen, ${ }^{1,4}$ Hao Liu, ${ }^{5}$ Ruyue Wang $\mathbb{D}^{6}$ \\ and Jingshou Liu $^{7}$ \\ ${ }^{1}$ College of Resources and Environmental Engineering, Guizhou University, Guiyang 550025, Guizhou, China \\ ${ }^{2}$ Key Laboratory of Karst Georesources and Environment, Ministry of Education, Guizhou University, Guiyang 550025, \\ Guizhou, China \\ ${ }^{3}$ College of Civil Engineering, Guizhou University, Guiyang 550025, Guizhou, China \\ ${ }^{4}$ Guizhou Institute of Technology, Guiyang 550003, Guizhou, China \\ ${ }^{5}$ College of Mining, Guizhou University, Guiyang 550025, Guizhou, China \\ ${ }^{6}$ SINOPEC Petroleum Exploration and Production Research Institute, Beijing 100083, China \\ ${ }^{7}$ Key Laboratory of Tectonics and Petroleum Resources of Ministry of Education (China University of Geosciences), \\ Wuhan 430074, China \\ Correspondence should be addressed to Zhonghu Wu; wuzhonghugzu@163.com
}

Received 8 November 2021; Revised 22 December 2021; Accepted 29 December 2021; Published 21 February 2022

Academic Editor: Qibin Lin

Copyright (C) 2022 Shuang Wang et al. This is an open access article distributed under the Creative Commons Attribution License, which permits unrestricted use, distribution, and reproduction in any medium, provided the original work is properly cited.

\begin{abstract}
The mineral components play an indispensable role in shale reservoirs, and the study of their content and character are significant for the permeability impairment rate and stress sensitivity of shale reservoirs. In this study, the shale cores from the FC1 well of the Lower Cambrian Niutitang Formation in northern Guizhou were used to analyze the mineralogical composition of five samples using X-ray diffractometry and for measurement of permeability and porosity of samples by means of the FYKS-2 hightemperature overburden porosimeter with $\mathrm{N}_{2}$, and the samples were also subjected to uniaxial compression tests using the INSTRON 1346 electrohydraulic servo-controlled material testing machine (200T), thereby analyzing the effect of mineral components on the permeability impairment rate and stress sensitivity coefficient of shale. Results indicate that the permeability and porosity are negatively correlated with effective stress and clay mineral content, and positively correlated with detrital mineral content, whereas, the change of mineral composition is not obvious for porosity. Simultaneously, the permeability impairment rate and stress sensitivity factor decrease with growing quartz content and modulus of elasticity, and increase with rising clay mineral content. Additionally, the greater the brittle minerals content of shale, the more likely it is to undergo brittle damage and more crack extension during compression with predominantly elastic deformation, resulting in a lower stress sensitivity factor. Conversely, the higher is the stress sensitivity factor. The research results further deepen the understanding of mineral components on the permeability and mechanical properties of shale reservoirs.
\end{abstract}

\section{Introduction}

The northern Guizhou shale gas is one of the blocks in the second round of shale gas tenders by the Ministry of Land and Resources and occupies an extremely important position among China's unconventional gas blocks. Its successful exploitation has made a significant contribution to enhancing China's energy structure and improving the ecological environment [1-5].
The study of shale maturation and formation evolution is based on the reservoir physical and petrographic characteristics of the shale, with diagenesis and tectonics playing a significant role in the formation and evolution of the shale [6-9]. The pore is the site of shale gas adsorption and storage [10-14], while natural fractures are the transport channels for shale oil and gas, both of which are inextricably linked to tectonic stress, mineral property, and mineral content [15-19]. Scholars have studied the characteristics of shale 
pore, formation and evolution mechanisms, and the distribution of brittle minerals under complex tectonics, and concluded that there is a correlation between shale pore and mineral property and distribution under complex tectonics [20-23]. Reservoir fracture prediction, as an important basis for delineating shale gas sweet spot areas, has the following two main prediction methods: qualitative and quantitative [24]. From the standpoint of qualitative prediction of fractures, both sides of the fracture zone, the end of the rupture, and the crack intersection are the zones of reservoir fracture development [25], while the methods of quantitative prediction of reservoir fractures such as fractal dimension, seismic and logging, and numerical simulation of tectonic stress field are becoming more and more mature [26-29]. The relationships between natural fractures, organic carbon content, mineral content, mineral properties, and distribution were derived from relevant tests and experiments on shale cores and outcrop samples from the Lower Cambrian Niutitang Formation in northern Guizhou [30-33]. In these rock samples, natural fractures are dominated by high angle tectonic fractures, which are filled to a degree of up to $95 \%$, and calcite is the main filling mineral $[2,34]$. The uniaxial and triaxial compression tests with multifield coupling properties are used to investigate the effects of laminae and mineralogical properties on the mechanical characteristics, permeability, and fracture extension of shale rocks, providing theoretical support for fracture modification and fracture extension mechanisms of shale gas reservoirs, thereby further improving the quality and efficiency of shale gas extraction [16, 26, 35-41].

In summary, scholars have performed many works to study the efficient extraction of shale gas, laying a solid theoretical foundation and technical guidance and providing feasible directions for later in-depth research. The mineral components play an indispensable role in shale reservoirs and have a significant impact on the permeability and mechanical properties of shale reservoirs. Scholars have focused on the correlation between mineral components and pore and natural fractures $[8,36,42-44]$, but little mention has been made of studies of mineral components on shale permeability impairment rate and stress sensitivity factor. Therefore, this study investigates the effect of mineral components on the permeability impairment rate and stress sensitivity factor of shales in the Lower Cambrian Niutitang Formation shale cores in northern Guizhou Province. The research achieved in this study further deepens the understanding of mineral components on the permeability and mechanical characteristics of shale, and provides theoretical support for fracture modification and fracture extension mechanisms in shale reservoirs.

\section{Geological Background of Northern Guizhou Province}

The research area is geotectonically situated in the Upper Yangzi Platform area, which is coherent with the regional tectonic evolution of the Yangzi Platform and geographically belongs to northern Guizhou province (Figure 1(a)) [21]. According to the history of tectonic development and evolution, Guizhou province is divided into four zones with different degrees of fracture development, including the developed zone, the relative developed zone, the moderately developed zone, and the undeveloped zone, in which the study region is situated in the fracture development zone (Figure 1(b)). The folds in the research area are mainly "spaced trough" structures with a series of northeast- and northsouth-oriented compound anticline and compound syncline structures [37]. The faults are mainly northeast- and north-northeast-oriented compressional-torsional faults, with multiple strike faults cutting and overlapping each other. The north-south tectonic zone is the earliest, followed by the north-northeast tectonic zone, and the northeast tectonic zone is the last to be formed. The nature of the faults can control the complexity of crack development; generally speaking, the density of fracture development is higher on compressional-torsional faults. Second, the influence of the type of tectonics on crack development and the density and penetration of crack development on the two flanks of the anticlines is lower than that on the axis (Figure 1(c)) $[23,28]$. The open-shelf depositional model is the main depositional environment for shale reservoirs of the Lower Cambrian Niutitang Formation in northern Guizhou. The argillaceous siltstone and silty mudstone are the main light-colored clastic facies in this sedimentary environment, while the silty carbonaceous mudstone belongs to the black clastic facies, and the limestone and dolomite are well developed, with thick overlying rock layers [22] (Figure 1(d)). The cores taken in this study are from the shale reservoir of the Lower Cambrian Niutitang Formation in northern Guizhou Province, which is also the main shale gas gathering formation (Figure 1(d)).

\section{Samples and Methods}

3.1. Samples. The samples were collected from the shale core of the FC1 well of the Lower Cambrian Niutitang Formation in northern Guizhou and were machined to approximately $25 \mathrm{~mm}$ in diameter and $50 \mathrm{~mm}$ in height (Table 1) [45], and were mainly grey-black siliceous shales. The mineralogical composition of the five samples was subjected by X-ray diffractometer (XRD), and the results of the analysis were as follows: quartz was the main constituent mineral in all five samples, with its content exceeding $49 \%$, with sample 1 containing over $80 \%$ quartz, the average is $68.91 \%$. The clay mineral content ranges from $3.03 \%$ to $29.93 \%$, and the average of $9.99 \%$, indicating that the shale cores of the FC1 well of the Lower Cambrian Niutitang Formation in northern Guizhou are predominantly brittle (Table 1) [45], followed by feldspar, pyrite, ankerite, and clay minerals, with a negative association between the quartz mineral composition and the clay mineral composition (Figure 2). The organic carbon content ranged from $3.54 \%$ to $8.12 \%$, which was on the high side.

\subsection{Experimental Theory}

3.2.1. Permeability and Porosity. The degree of shale gas transport is closely related to permeability and porosity, and when porosity is developed and penetrates natural fractures, 


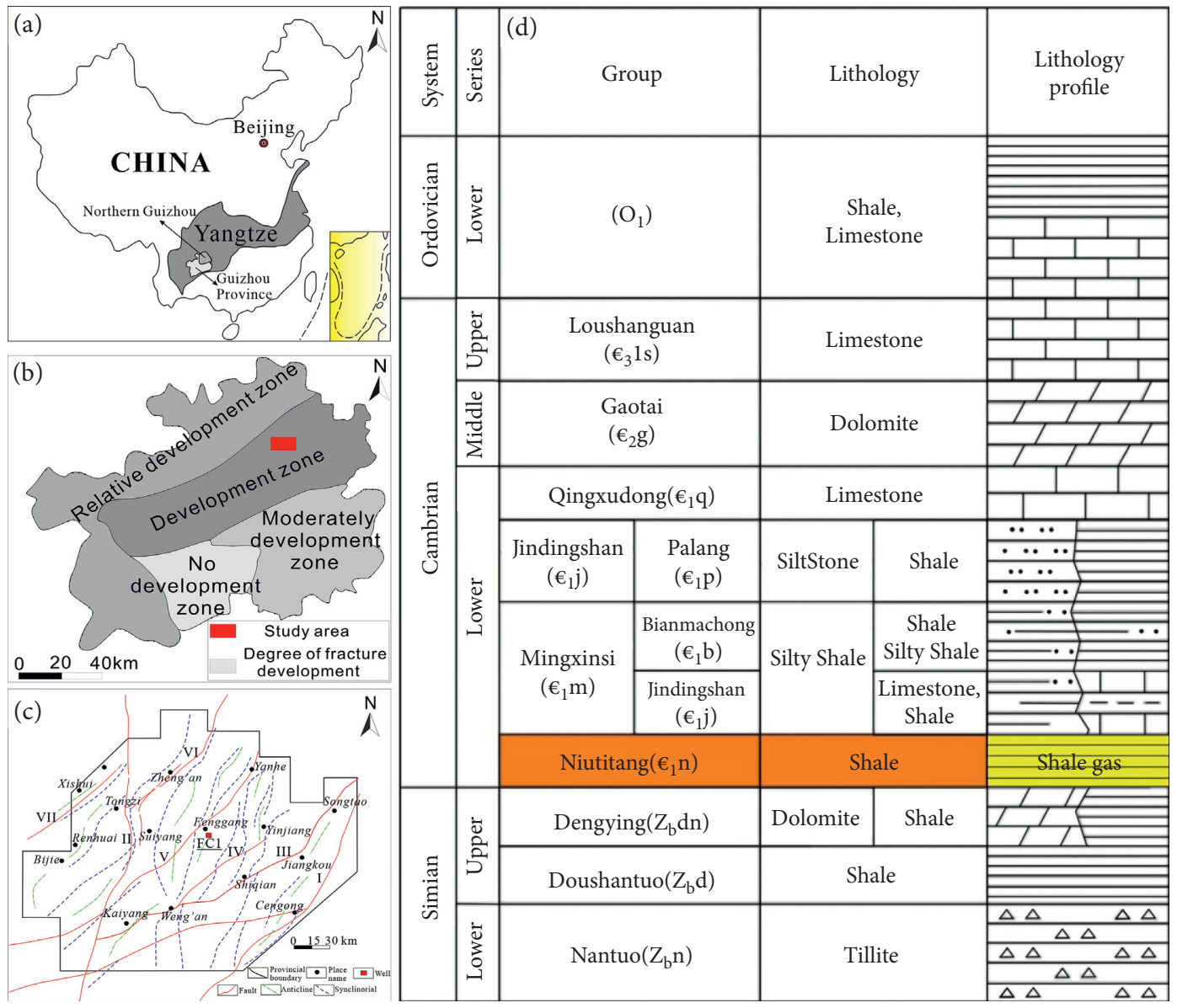

FIGURE 1: Regional geological overview of the study area ((a) location of the study area; (b) extent of fracture development; (c) tectonic development; (d) stratigraphic lithological profile).

TABLE 1: Basic sample parameters and mineral content.

\begin{tabular}{lccccccccccc}
\hline $\begin{array}{l}\text { Sample } \\
\text { ID }\end{array}$ & $\begin{array}{c}\text { Test core size } \\
\text { Liameter }\end{array}$ & $\begin{array}{c}\text { Permeability } \\
\left(10^{-3} \mu \mathrm{m}^{2}\right)\end{array}$ & $\begin{array}{c}\text { Porosity } \\
(\%)\end{array}$ & \multicolumn{5}{c}{ Mineralogical composition (\%) } \\
\hline 1 & 50.0 & 25.23 & 0.0060 & 1.67 & 81.83 & 3.11 & 0.00 & 9.95 & 2.08 & 3.03 & Dry \\
2 & 51.0 & 25.27 & 0.0052 & 1.62 & 49.91 & 14.01 & 1.99 & 1.99 & 2.16 & 29.93 & Dry \\
3 & 50.5 & 25.21 & 0.0071 & 1.85 & 65.92 & 16.96 & 1.04 & 2.94 & 7.09 & 6.055 & Dry \\
4 & 51.0 & 25.30 & 0.0073 & 1.80 & 66.90 & 18.02 & 1.99 & 0.95 & 5.20 & 6.93 & Dry \\
5 & 49.0 & 25.20 & 0.0056 & 1.56 & 79.98 & 3.90 & 5.20 & 0.00 & 6.93 & 3.99 & Dry \\
\hline
\end{tabular}

it can provide a good permeable transport channel for shale gas [36]. The permeability and porosity of the samples were measured using the FYKS-2 high-temperature overburden pore permeability tester with $\mathrm{N}_{2}$. All collected permeability and porosity data were recorded and calculated by computer (Table 1). The relationship between permeability, porosity, and stress in shale reservoirs is analyzed by increasing the net shale confining pressure to simulate the effective stress changes in the shale reservoir and recording the changes in shale permeability and porosity at different net confining pressures. And on this basis, the effect of mineral components in shale on permeability and porosity is analyzed. Five equal gradients of net perimeter pressure values of $3 \mathrm{MPa}$, $5 \mathrm{MPa}, 7 \mathrm{MPa}, 9 \mathrm{MPa}$, and $11 \mathrm{MPa}$ were set for each sample in turn. Each stress point is held stable for at least 30 minutes before the permeability value of the sample at that stress point can be determined.

Porosity is the percentage of the effective pore volume to the volume of core particles in the sample and is expressed as follows:

$$
\phi=\frac{V_{a}}{V_{a}+V_{f}} \times 100 \%,
$$

where $V_{a}$ represents the effective pore volume of the core and $V_{f}$ represents the volume of the core particles.

According to Darcy's law, when $\mathrm{N}_{2}$ flows through the measured sample under a certain pressure, the expression for the measured permeability is as follows: 


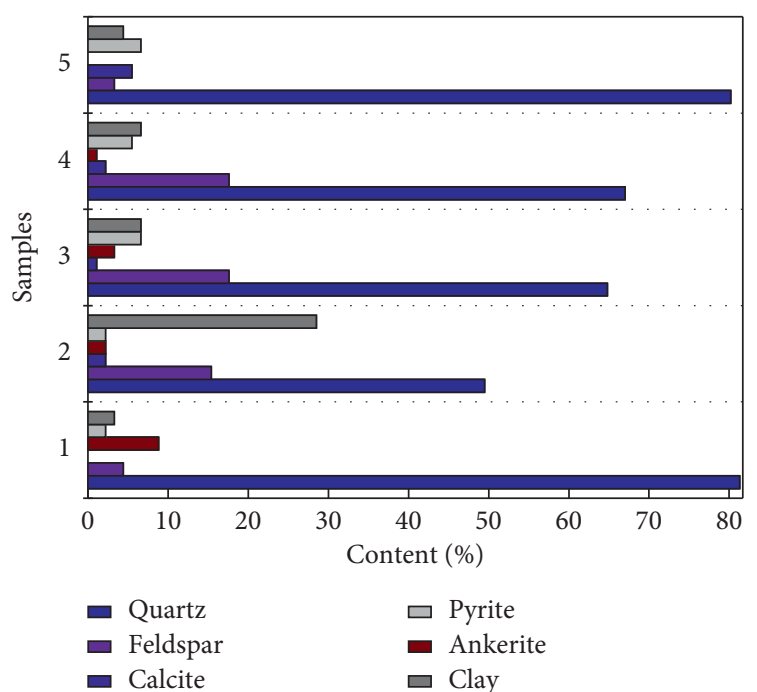

Figure 2: Sample mineral content.

$$
K_{g}=\frac{2 p Q_{0} u L}{A\left(p_{1}^{2}-p_{2}^{2}\right)} \times 10^{2}
$$

where $K_{g}$ is the permeability, $10^{-3} \mu \mathrm{m}^{2} ; p$ and $Q_{0}$ are the standard atmospheric pressure of the test environment and the volume of $\mathrm{N}_{2}$ passing through the sample in a given time, $\mathrm{MPa}$ and $\mathrm{cm}^{3} / \mathrm{s}$, respectively; $u$ and $L$ are the fluid viscosity and sample height, $\mathrm{MPa} \cdot \mathrm{s}$ and $\mathrm{cm}$, respectively; $p_{1}$ and $p_{2}$ are the sample inlet and outlet pressures, $\mathrm{MPa}$, respectively; and $A$ is the transverse area of the sample, $\mathrm{cm}^{2}$.

3.2.2. Uniaxial Compression Test. The physical characteristics of shale reservoirs are highly related to the mineral fraction, mineral content, the level of natural crack development, etc. When shale reservoirs have a high content of brittle minerals, showing a significantly great modulus of elasticity and a low Poisson's ratio [17, 31, 46]. To further understand the effect of reservoir properties on shale permeability damage rate and stress sensitivity, an INSTRON 1346 electrohydraulic servo-controlled material testing machine (200T) was used to perform uniaxial compression tests on five shale samples with axial loading and selected displacement control, the test axial displacement loading rate was $0.01 \mathrm{~mm} / \mathrm{min}$, and the loading equipment and schematic diagram are shown in Figure 3.

\section{Results}

\subsection{Effect of Factors on Shale Permeability and Porosity}

4.1.1. Effect of Effective Stress on Shale Permeability and Porosity. Referring to the Chinese oil and gas industry standard "Experimental Evaluation Method of Reservoir Sensitive Flow" (SY/T 5358-2010), the changes of shale permeability and porosity under different effective stresses are shown in Figure 4.

Computer fitting of the shale permeability and porosity variation data at different effective stresses shows that

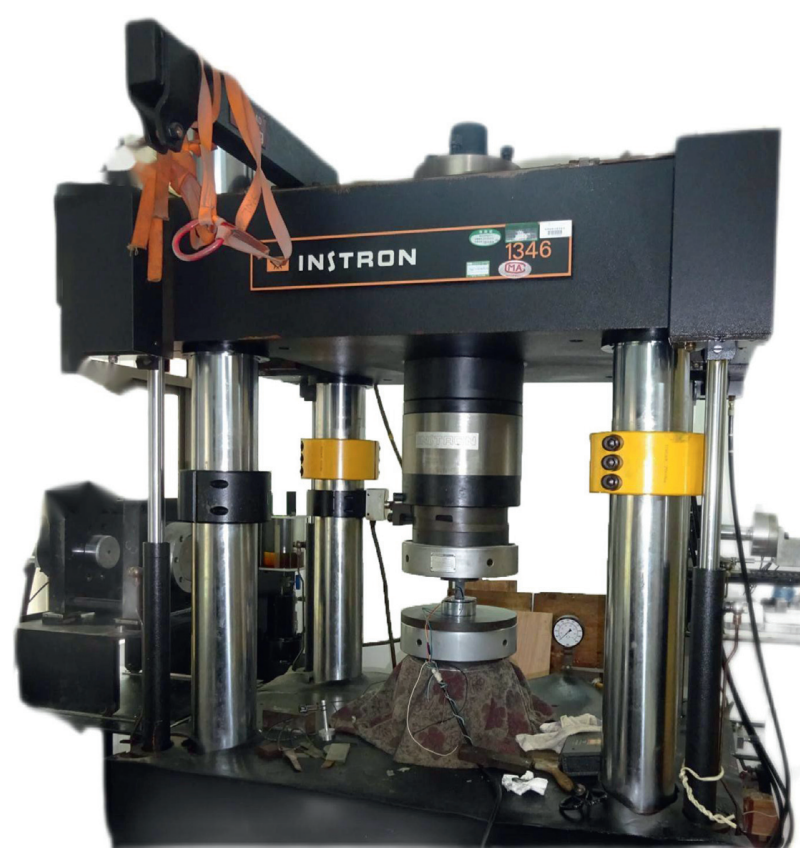

FIGURE 3: Stress loading diagram.

permeability and porosity of the samples both decrease with growing effective stress, with a negative index relationship and a good fit. Nevertheless, when the effective stress exceeds $9 \mathrm{MPa}$, the decrease of permeability and porosity of shale reduces, indicating that the confining pressure in deepburied strata significantly controls the permeability and porosity of shale reservoirs.

4.1.2. Effect of Mineral Components on Shale Permeability and Porosity. The mineral components play an integral role in shale reservoirs, and the physical properties of shale reservoirs vary according to their mineral content and property. When brittle minerals are developed, the higher the natural fracture density in the shale, which helps shale gas transport and reservoir fracture modification. When carbonate rocks are developed, shales tend to create dissolution pores during hydrocarbon evolution, increasing the adsorption and free sites for shale gas. The pore volume in the shale is negatively correlated with the clay mineral content, which is not conducive to the permeable transport of shale gas. The effect of mineral components on shale porosity and permeability is analyzed in terms of detrital minerals (quartz + feldspar + ankerite + calcite) and clay mineral content (Figure 5). The permeability increases with increasing detrital mineral content and decreases with increasing clay mineral content. This is because the higher the brittleness of the shale, the higher the density of natural fracture development, which acts as a good channel for seepage $[31,36]$. The porosity increases slightly with increasing detrital mineral content and decreases marginally with increasing clay mineral content. Nevertheless, the higher the detrital mineral content the smaller the porosity as the surrounding pressure increases, and even less than the clay mineral content under high surrounding pressure 


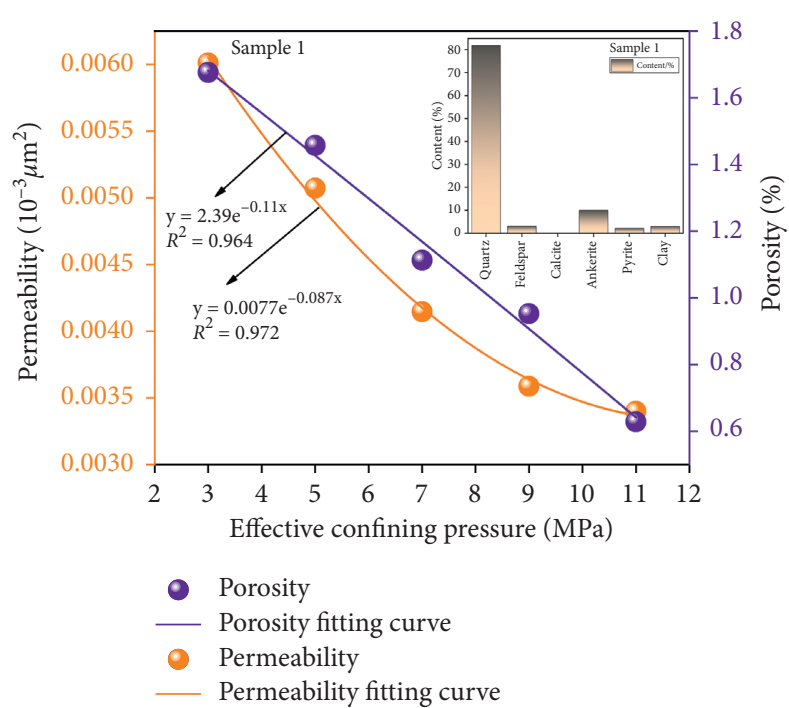

(a)

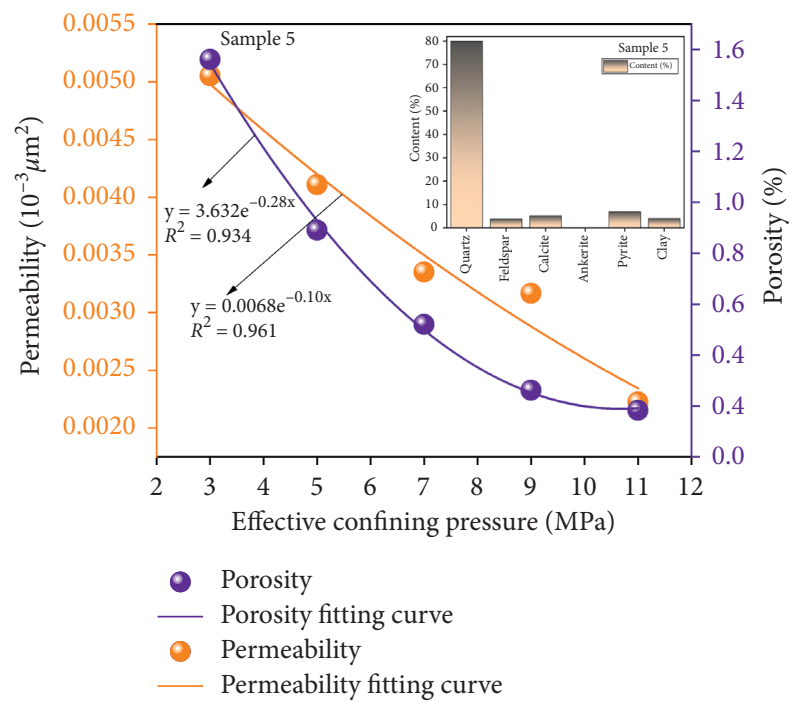

(c)

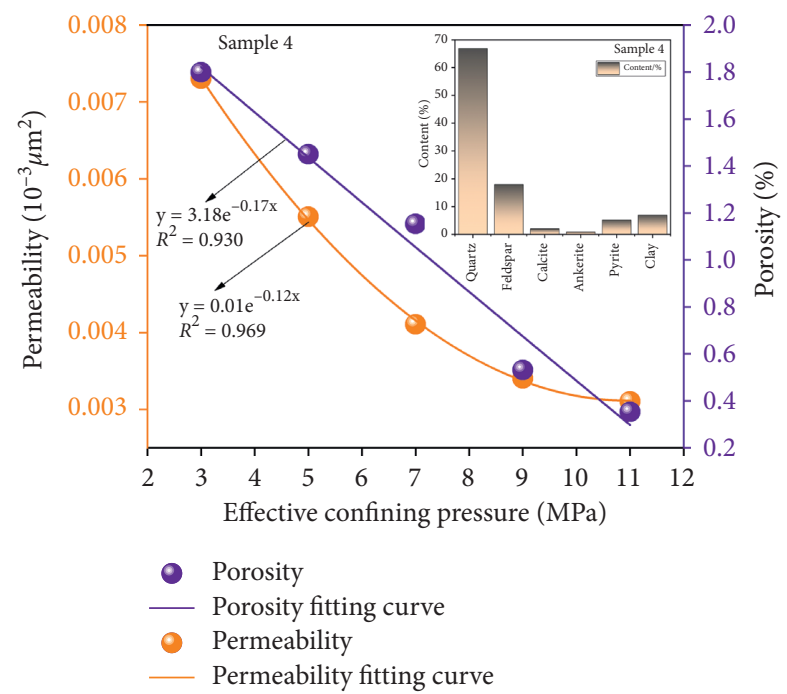

(e)

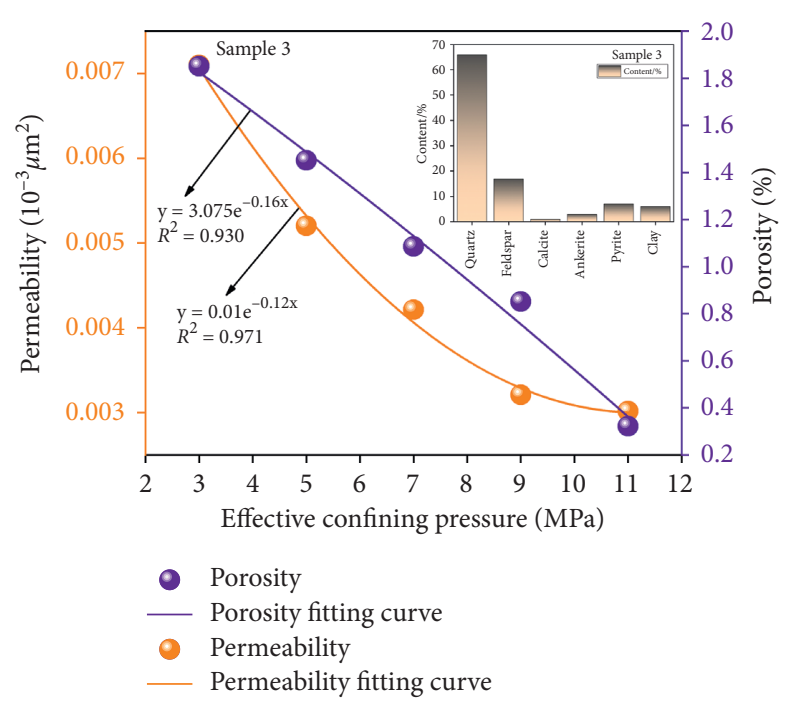

(b)

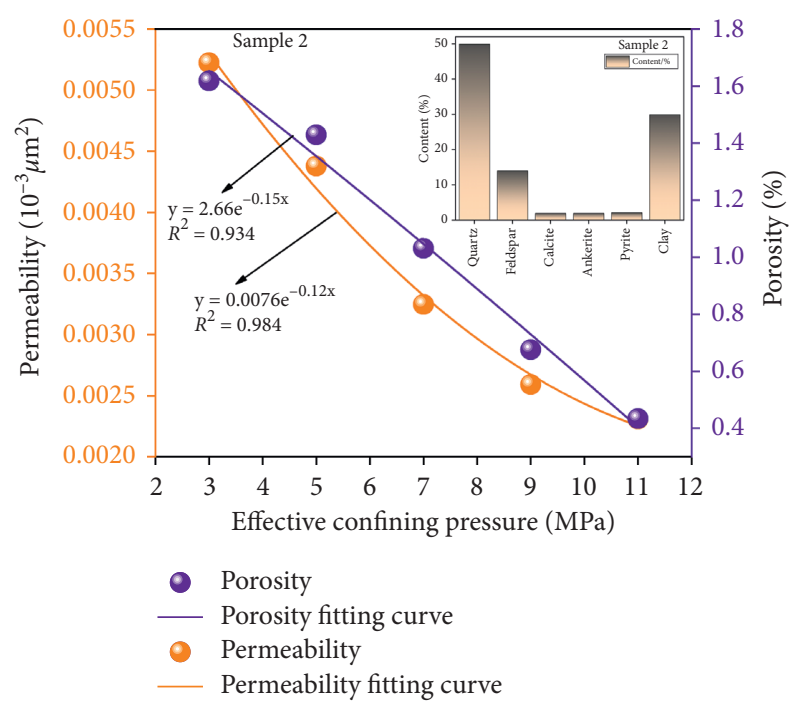

(d)

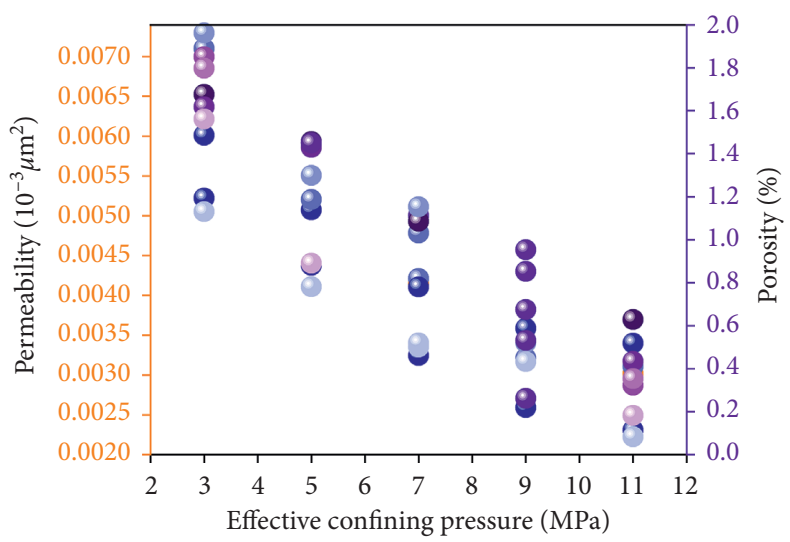

$\begin{array}{ll}\text { Porosity } & \text { Porosity } \\ \text { - Sample 1 } & \text { - Sample 1 } \\ \text { - Sample 2 } & \text { - Sample 2 } \\ \text { - Sample 3 } & \text { - Sample 3 } \\ \text { - Sample 4 } & \text { - Sample 4 } \\ \text { - Sample 5 } & \text { - Sample 5 }\end{array}$

(f)

FIGURE 4: Variation in shale permeability and porosity under different effective stresses. 


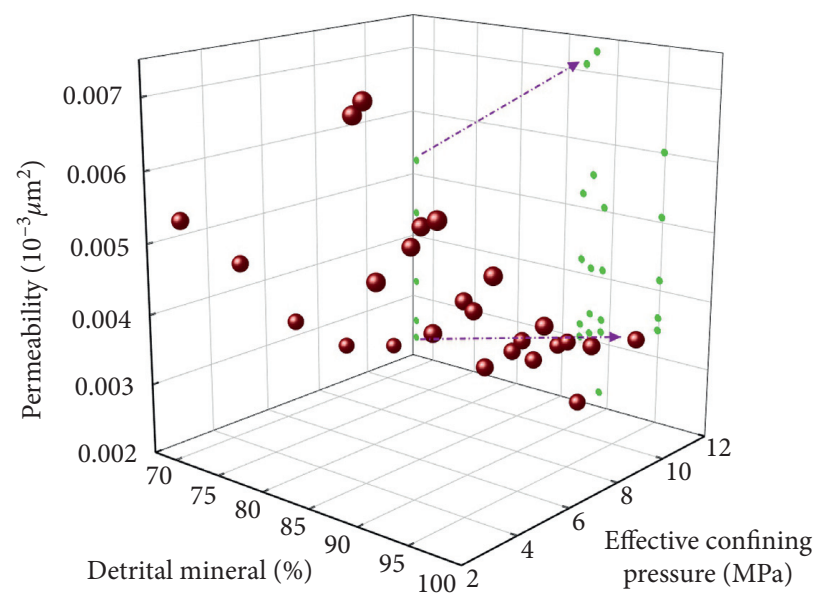

(a)

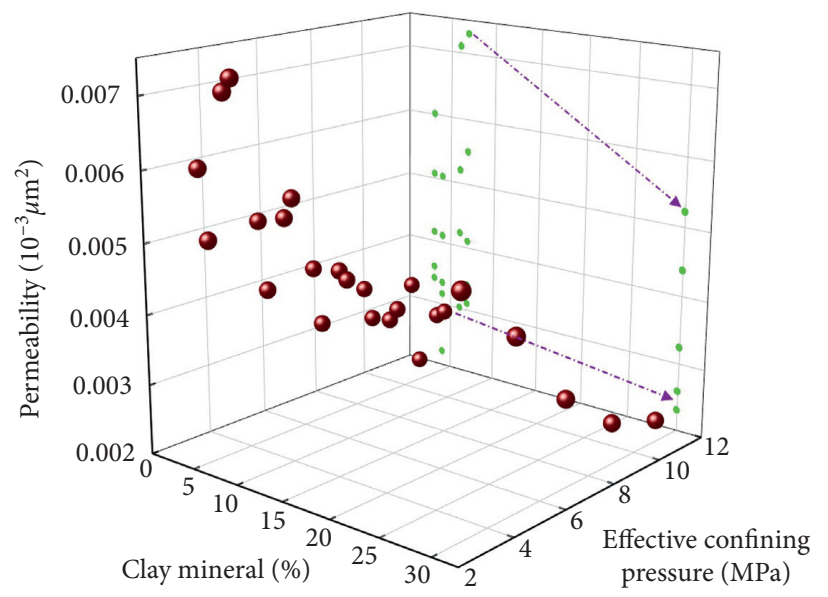

(c)

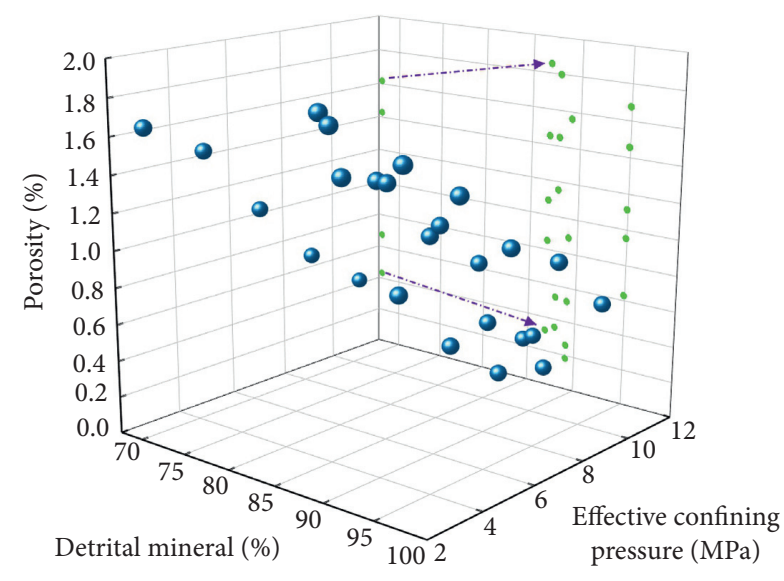

(b)

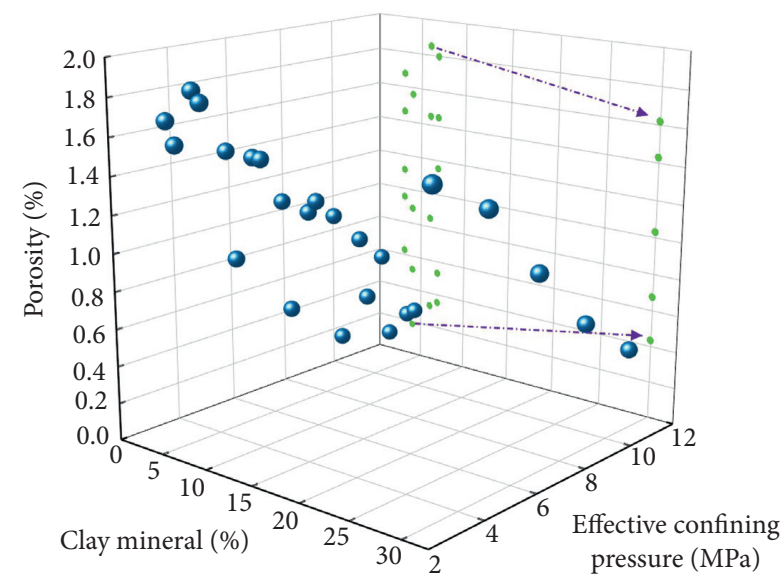

(d)

FIGURE 5: Relationship between mineral components and permeability and porosity.

conditions. This is due to the development of carbonate minerals in the detrital minerals, which are easily dissolved by exfoliation during the maturation and evolution of the shale to form dissolved pores. Nevertheless, when the surrounding pressure increases to the ultimate strength of the pores, they are compacted and closed, resulting in a reduction in porosity in the shale. The low compressive resistance of clay minerals makes it difficult to protect the intrinsic pores, and when the surrounding pressure exceeds the ultimate strength, the shale deforms plastically, resulting in some of the pores in the shale not being compacted and closed [22]. Therefore, the porosity in the detrital minerals is less than that in the clay minerals under high surrounding pressure conditions.

\subsection{The Permeability Damage Rate and Stress Sensitivity} Factor. As there is no industry standard for shale sensitivity, reference was made to the Method for Determination of Porosity and Permeability of Rocks under Overburden Pressure (SY/T 6385-2016) and the Method for Experimental Evaluation of Reservoir Sensitivity Flow (SY/T 53582010) for the test analysis. From the above findings, it can be concluded that the porosity of the sample has a negative index dependence on the effective stress, and therefore the correlation between the compression factor and the effective stress is derived as follows:

$$
m=\frac{\ln \phi_{0}-\ln \phi}{p_{e}},
$$

where $m$ is the compression coefficient, $\mathrm{MPa}^{-1} ; \phi_{0}$ and $\phi$ are the porosity at the initial stress and the porosity at the specified effective stress, \%, respectively; and $p_{e}$ is the specified effective stress, MPa.

At the same time, the percolation rate is also negatively exponentially associated with the effective stress, resulting in the permeability stress sensitivity factor relationship

$$
n=\frac{\ln k_{0}-\ln k}{p_{e}},
$$

where $k_{0}$ and $k$ are the permeability at the initial stress and the permeability at the specified effective stress, $10^{-3} \mu \mathrm{m}^{2}$, respectively; and $n$ is the permeability stress sensitivity factor, $\mathrm{MPa}^{-1}$. The compressibility coefficient and permeability stress sensitivity coefficient of samples under different effective stresses can be obtained by formulas (3) and (4) (Table 2). 
TABLE 2: Compression coefficients and permeability stress sensitivity coefficients of samples at different effective stresses.

\begin{tabular}{lcccc}
\hline Sample ID & Stress sensitivity coefficient $n\left(\mathrm{MPa}^{-1}\right)$ & Compressibility $m\left(\mathrm{MPa}^{-1}\right)$ & Porosity $\phi_{0}(\%)$ & Permeability $k_{0}\left(10^{-3} \mu \mathrm{m}^{2}\right)$ \\
\hline 1 & 0.0866 & 0.1093 & 2.3858 & 0.0077 \\
2 & 0.1222 & 0.1457 & 2.6589 & 0.0076 \\
3 & 0.1198 & 0.1586 & 3.0753 & 0.0099 \\
4 & 0.1201 & 0.1720 & 3.1822 & 0.0102 \\
5 & 0.1027 & 0.2814 & 3.6318 & 0.0067 \\
\hline
\end{tabular}

In this article, permeability impairment rate and stress sensitivity factor are used to estimate the stress sensitivity of shale reservoirs [47], with permeability damage rate defined as follows:

$$
D_{k_{\max }}=\left[\frac{\left(k_{1}-k_{\min }^{\prime}\right)}{k_{1}}\right] \times 100 \%,
$$

where $k_{1}$ and $k_{\min }^{\prime}$ are the permeability corresponding to the first effective stress and the minimum value of permeability corresponding to the process of reaching the critical stress, $10^{-3} \mu \mathrm{m}^{2}$, respectively and $D_{k_{\max }}$ is the maximum rate of permeability impairment corresponding to the increase in effective stress to a maximum value.

Secondly, the stress sensitivity coefficient is defined as follows [48]:

$$
a_{k}=\frac{(-\partial k)}{\left(k_{0} \partial p\right)} .
$$

From equation (6), the greater the change in sample permeability for equal magnitude changes in effective stress, the greater the $a_{k}$ and the greater the sensitivity. Conversely, the smaller it is.

The permeability impairment rates and stress sensitivity coefficients for samples at different effective stresses were calculated from the above equations (Table 3), and the effect of mineral components in samples on the permeability impairment rate and stress sensitivity factor of shale was analyzed (Figures 5 and 6).

\subsection{Effect of Factors on Shale Permeability Damage Rates and Stress Sensitivity Coefficients}

4.3.1. Effect of Quartz Content on Shale Permeability Damage Rates and Stress Sensitivity Coefficients. As shown in Figure 6, the permeability impairment rate of the samples grows with growing effective stress, whereas, the trend varies somewhat from sample to sample. Samples 2, 3, and 4 had much greater permeability damage rates than samples 1 and 5 due to the smaller quartz content in samples 2,3 , and 4 . Nevertheless, samples 1 and 5 have a high quartz content and show a decrease in the degree of change in permeability damage rate with increasing quartz content at different effective stresses, especially in samples with high quartz content, such as samples 1 and 5. In contrast, the permeability damage rate does not vary much at different effective stresses for smaller quartz contents, such as in samples 2, 3, and 4 . The stress sensitivity factor of the samples reduces with growing effective stress, whereas, the trend varies somewhat from sample to sample. Samples 2, 3, and 4 have much larger stress sensitivity coefficients than samples 1 and 5 due to the smaller quartz content in samples 2, 3, and 4 . Nevertheless, samples 1 and 5 have a high quartz content and show a decrease in the stress sensitivity coefficient with increasing quartz content at different effective stresses, with samples 1 and 5, in particular, showing the most prominent pattern. In contrast, with the smaller quartz content, the stress sensitivity coefficient does not change much at different effective stresses, such as in samples 2, 3, and 4 . The stress sensitivity coefficient converges at effective stress of $11 \mathrm{MPa}$, irrespective of the percentage of quartz content in the sample. Nevertheless, the tendency for the stress sensitivity coefficient to level off with increasing effective stress is greater for samples with higher quartz content, and the stress sensitivity coefficient will ultimately be greater for samples with higher quartz content than for those with lower quartz content.

\subsubsection{Effect of Different Mineral Contents and Properties on} Shale Permeability Damage Rates and Stress Sensitivity Coefficients. The mineral property and mineral content of the shale determine the physical properties of the shale reservoir, for example, highly brittle minerals have a good ability to induce fractures and generate fractures $[36,43,49]$. The greater the content of brittle minerals in the shale, the easier it is for the shale reservoir to be fractured and modified to create a sophisticated crack network, and the development of brittle minerals in shale is a desirable element for shale gas exploitation [31]. The mineralogical composition of the five samples was measured using an $\mathrm{X}$-ray diffractometer, which showed that quartz was the main constituent mineral in the five samples, along with feldspar, pyrite, ankerite, and clay minerals in that order. The quartz content of the samples ranged from $49.91 \%$ to $81.83 \%$, with a mean of $68.91 \%$, and the clay mineral content ranged from $3.03 \%$ to $29.93 \%$, with a mean of $9.99 \%$, indicating that the shale core of the FC1 well of the Lower Cambrian Niutitang Formation in northern Guizhou is predominantly brittle. In terms of different mineral contents, sample 2, for example, has the smallest quartz content, whereas, the highest stress sensitivity coefficient and permeability damage rate of $0.05511 \mathrm{MPa}^{-1}$ and $55.05 \%$, respectively. Sample 1 had the highest quartz content, whereas, the lowest stress sensitivity coefficient and permeability damage rate of $0.04867 \mathrm{MPa}^{-1}$ and $43.91 \%$, respectively. Samples 3 and 4 had similar quartz content, and therefore similar stress sensitivity coefficients and permeability damage rates for both samples (Figure 7). Conversely, sample 2, for example, had the highest clay mineral content, and correspondingly 
Table 3: Permeability damage rates and stress sensitivity coefficients for samples at different effective stresses.

\begin{tabular}{|c|c|c|c|c|c|}
\hline \multirow{3}{*}{ Sample ID } & \multicolumn{5}{|c|}{$($ Permeability damage rate $(\%)) /\left(\right.$ stress sensitivity coefficient $\left.\left(\mathrm{MPa}^{-1}\right)\right)$} \\
\hline & \multicolumn{5}{|c|}{ Effective confining pressure $(\mathrm{MPa})$} \\
\hline & 3 & 5 & 7 & 9 & 11 \\
\hline 1 & $22.89 / 0.0668$ & $35.16 / 0.0561$ & $45.44 / 0.0470$ & $54.39 / 0.0397$ & $61.69 / 0.0334$ \\
\hline 2 & $30.87 / 0.0850$ & $45.87 / 0.0663$ & $57.76 / 0.0521$ & $66.72 / 0.0410$ & $74.04 / 0.0317$ \\
\hline 3 & $30.13 / 0.0839$ & $45.06 / 0.0660$ & $56.71 / 0.0516$ & $66.07 / 0.0409$ & $73.31 / 0.0324$ \\
\hline 4 & $30.29 / 0.0839$ & $45.28 / 0.0660$ & $56.84 / 0.0518$ & $66.12 / 0.0407$ & $73.29 / 0.0322$ \\
\hline 5 & $26.50 / 0.0755$ & $40.18 / 0.0615$ & $51.23 / 0.0502$ & $60.31 / 0.0408$ & $67.58 / 0.0334$ \\
\hline
\end{tabular}

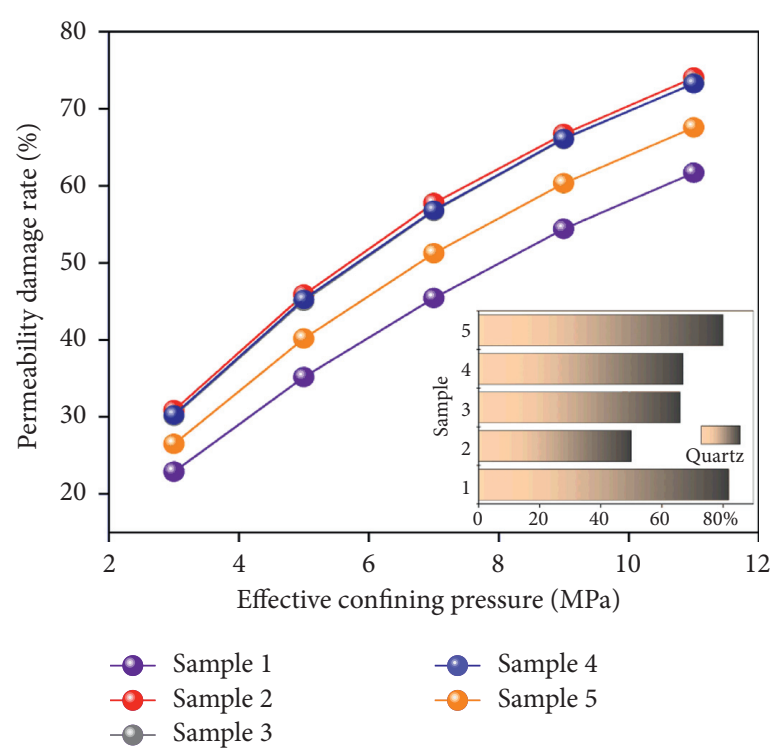

(a)

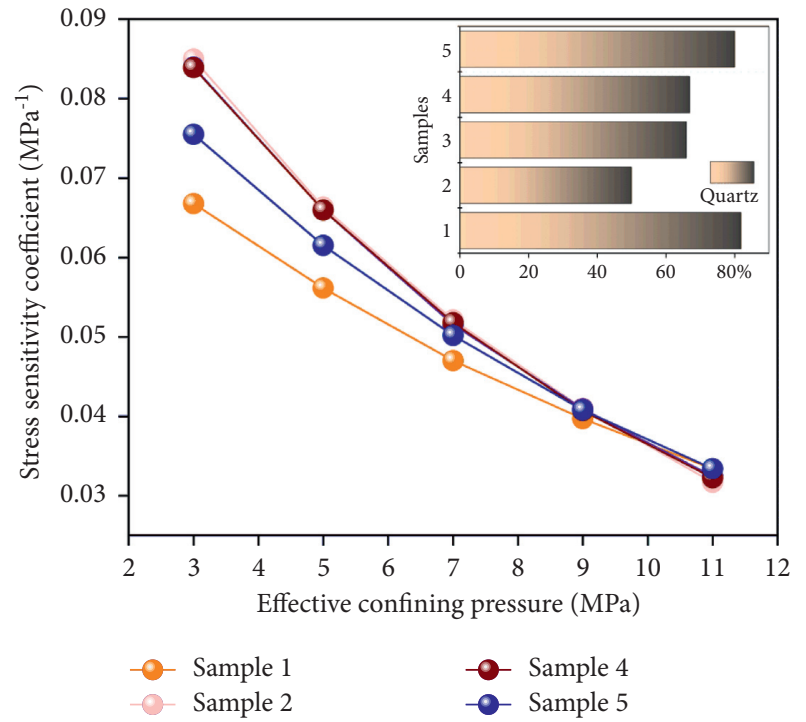

(b)

FIGURE 6: Relationship between quartz content and permeability damage rate and stress sensitivity coefficient.

the highest stress sensitivity coefficient and permeability damage rate of $0.05511 \mathrm{MPa}^{-1}$ and $55.05 \%$, respectively. Sample 1 had the lowest clay mineral content, and correspondingly the lowest stress sensitivity factor and permeability impairment rate of $0.04867 \mathrm{MPa}^{-1}$ and $43.91 \%$, respectively (Figure 7). From a mineralogical point of view, the stress sensitivity factor and the permeability impairment rate decrease with increasing quartz content, with a negative correlation. The stress sensitivity factor and the permeability impairment rate increase with growing clay and feldspar mineral content, with a positive correlation. Nevertheless, the change of feldspar mineral content is not obvious for the permeability impairment rate and stress sensitivity factor (Figure 7). Consequently, the above suggests that there is some influence of different mineral contents and properties on shale permeability damage rates and stress sensitivity coefficients.

\subsubsection{Effect of Mechanical Parameters on Shale Permeability} Damage Rates and Stress Sensitivity Coefficients. Quantitative analysis of the whole rock mineral content by $\mathrm{XRD}$ as described above indicates that the shale core of the FC1 well of the Lower Cambrian Niutitang Formation in northern Guizhou is a predominantly brittle mineral (Table 1). When the shale has a great brittle mineralogical composition, the mechanical properties are characterized by a high modulus of elasticity and a low Poisson's ratio [46]. The influence of the mineral content and mineral characteristics of the sample during compression, for example, quartz has a strong resistance to compression densities among brittle minerals and is the main supporting mineral for the mechanical properties of the shale matrix. The uniaxial compression tests on five shale samples using an INSTRON 1346 electro-hydraulic servo-controlled material testing machine (200T) showed that the modulus of elasticity ranged from 20.46 to $27.53 \mathrm{GPa}$, with an average of 24.27 GPa, sample 1 had the highest modulus of elasticity at $27.53 \mathrm{GPa}$, and sample 2 had the lowest modulus of elasticity at $20.46 \mathrm{GPa}$, with positive and negative correlations between modulus of elasticity and quartz and clay content, respectively (Figure 8). The modulus of elasticity is an essential parameter in dictating the mechanical characteristics of shale reservoirs, and consequently, the modulus of elasticity can be used as an important indicator in the evaluation of the permeability impairment rate and stress sensitivity factor of shale reservoirs. As shown in Figure 9, both the shale permeability impairment rate and the stress 


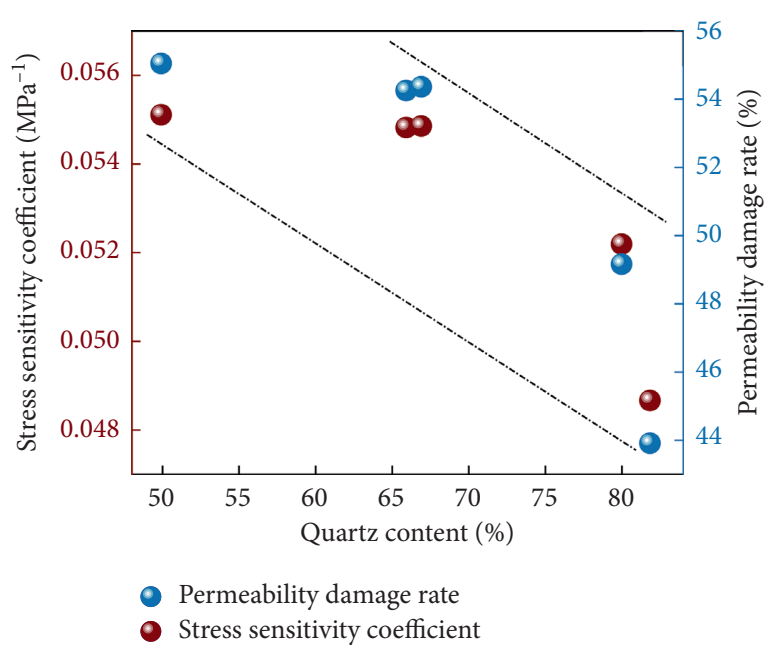

(a)

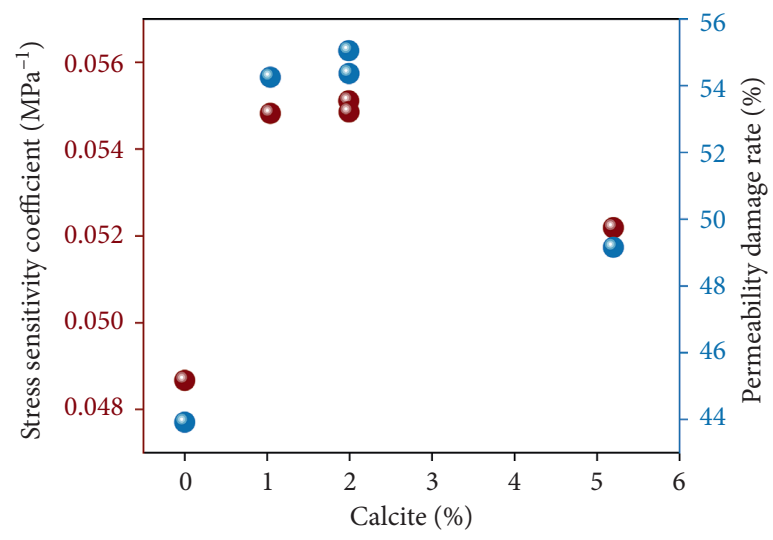

- Permeability damage rate

- Stress sensitivity coefficient

(c)

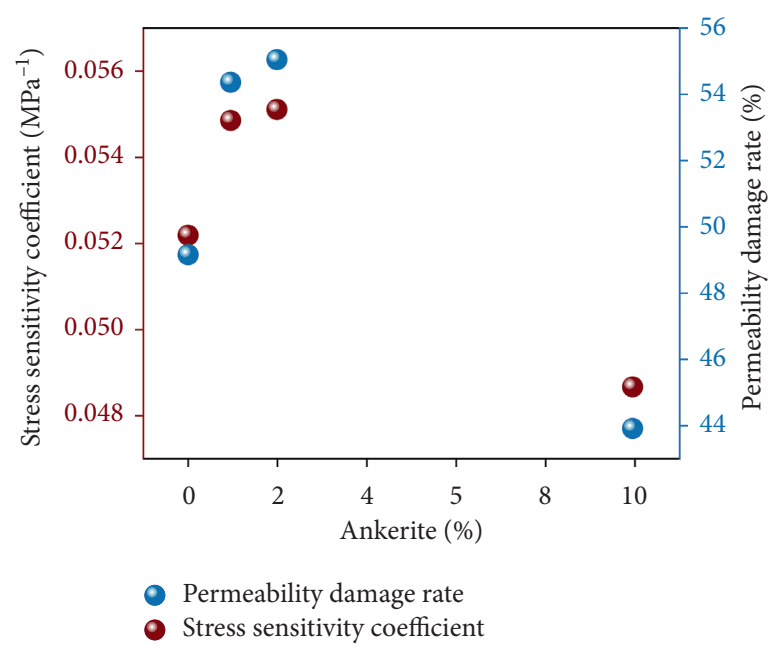

(e)

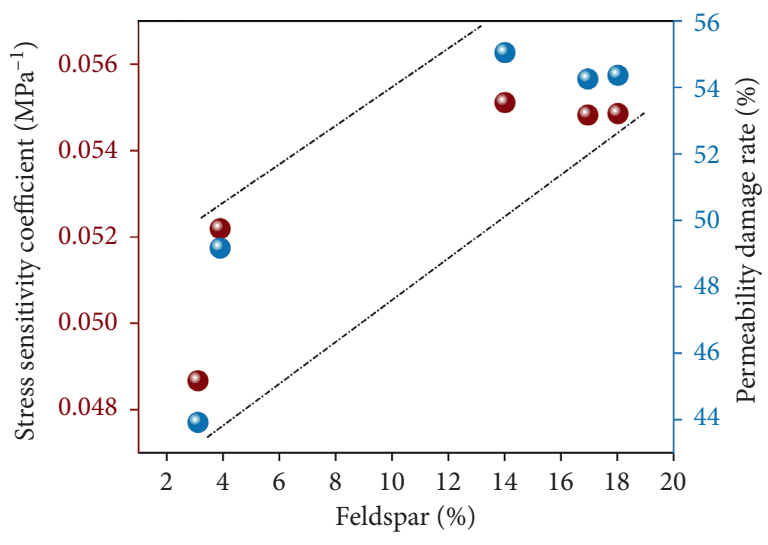

Permeability damage rate

Stress sensitivity coefficient

(b)

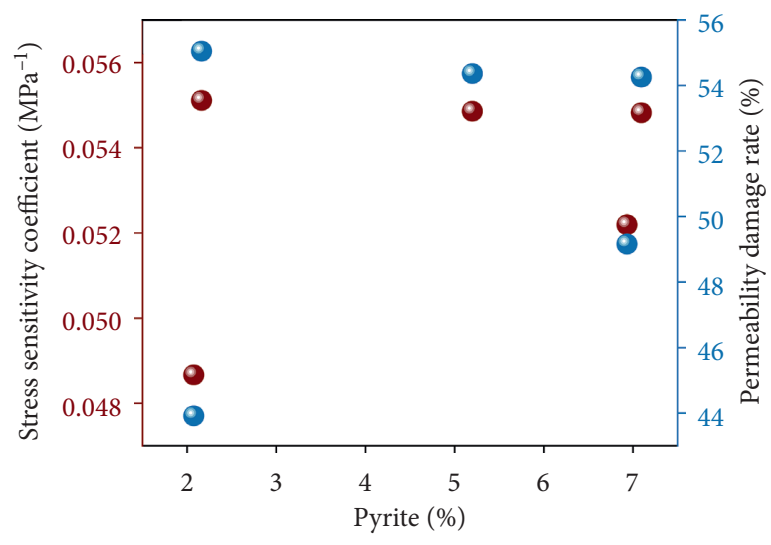

Permeability damage rate

Stress sensitivity coefficient

(d)

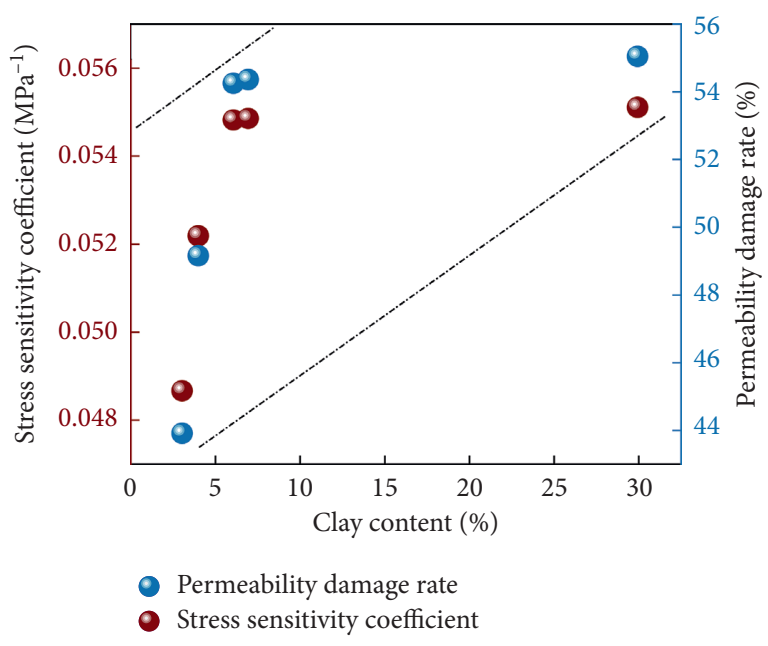

(f)

FIGURE 7: Relationships between mineral components and shale permeability impairment rates and stress sensitivity factors.

sensitivity factor decrease with the increasing modulus of elasticity. Of these, sample 1 had the highest modulus of elasticity, whereas, sample 1 had the lowest stress sensitivity factor and permeability impairment rate. Sample 2 had the lowest modulus of elasticity, whereas, sample 2 had the highest stress sensitivity factor and permeability impairment 


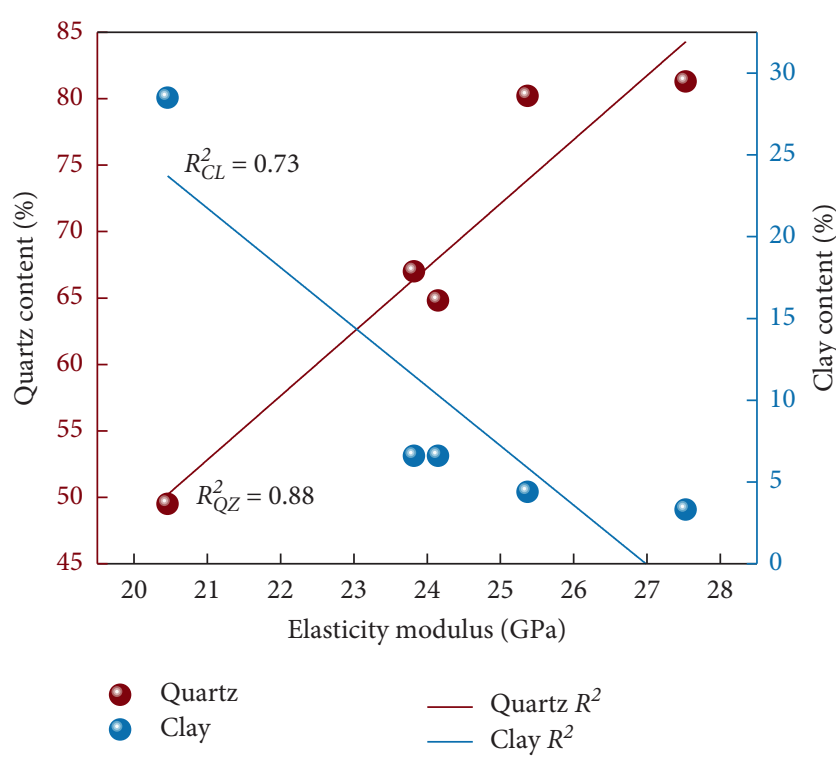

Figure 8: Modulus of elasticity as a function of quartz and clay mineral content.

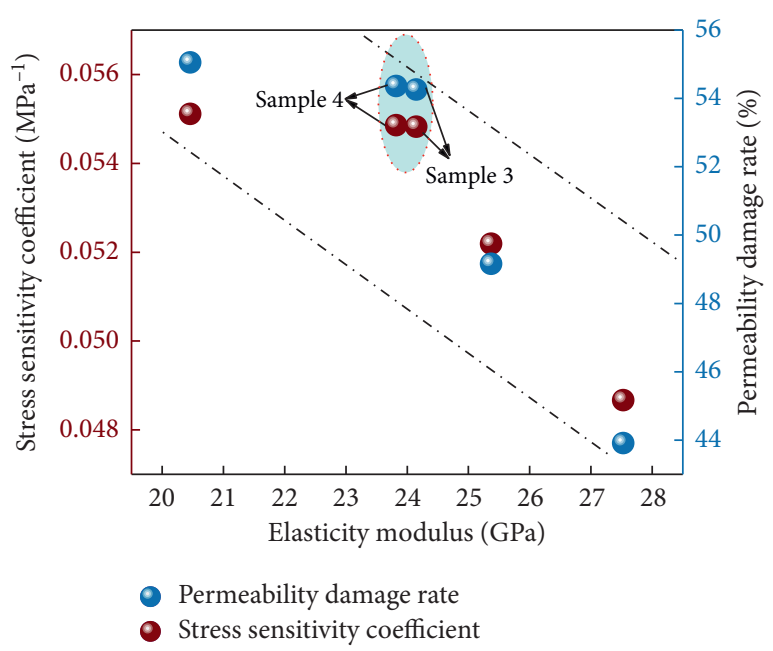

Figure 9: Relationship between modulus of elasticity and stress sensitivity coefficient and permeability damage rate of shale.

rate. The trend of elastic modulus to shale stress sensitivity factor and permeability impairment rate is consistent with the quartz content, indicating that the stress sensitivity factor and permeability impairment rate are related to the hardness of the shale, consequently, the compression coefficient parameter of the rock skeleton is introduced here [50]:

$$
C_{p}=\frac{\phi}{1-\phi} C_{s}=\frac{\phi}{1-\phi} \frac{3(1-2 \mu)}{E},
$$

where $C_{p}$ and $C_{s}$ are the compression coefficient and skeletal compression coefficient of the shale, respectively; $E$ and $\mu$ are the modulus of elasticity and Poisson's ratio of the shale, respectively; and $\phi$ is the porosity of the shale.

As shown in equation (7), the greater the quartz content of the shale, the higher the modulus of elasticity, and the harder the skeleton, the lower the compression coefficient of the shale. Conversely, the greater the clay mineral content of the shale, the smaller the modulus of elasticity, and the weaker the skeleton, the higher the compression coefficient of the shale.

In Figure 9, we can also identify a problem in that although sample 3 has a slightly smaller quartz content than sample 4 , sample 3 has a slightly higher modulus of elasticity than sample 4, resulting in opposite trends in the stress sensitivity coefficients and permeability damage rates for sample 3 and sample 4 . The reason for this is therefore analyzed from the perspective of porosity. As can be seen from Figure 10, sample 4 has a higher quartz content than sample 3, but sample 4 has a lower modulus of elasticity than sample 3, while the porosity magnitudes of the two are reversed. Samples 1 and 5 are close in quartz content and sample 1 has a higher modulus of elasticity than sample 5, whereas, they also have opposite porosity sizes. A comparison of the elastic modulus magnitudes of these two groups of shale samples with similar quartz content shows that there is a definite effect of porosity size on the mechanical parameters of the shale samples with similar quartz content. This is shown by the fact that when the quartz content of the shale is similar, the greater the modulus of elasticity, the lower the porosity, smaller the modulus of elasticity with greater porosity. Nevertheless, the general trend of decreasing stress sensitivity coefficients and permeability damage rates for shales with the increasing modulus of elasticity has not changed.

\subsubsection{Effect of Porosity on Shale Permeability Impairment} Rate and Stress Sensitivity Factor at Initial Effective Stress. According to scholarly research, the porosity in the shale core of the FC1 well of the Lower Cambrian Niutitang Formation in northern Guizhou is mainly divided into intergranular pores, intragranular pores, and organic matter pores [51, 52]. The degree of porosity development is one of the most essential factors in determining the adsorption and resolution of shale gas, and when the pore space is articulated with natural fractures, it can also control shale gas transport and is an important parameter in the extraction of industrial shale gas [53]. The degree of porosity development is inextricably linked to mineral content and mineral property, with a positive relationship between porosity and brittle mineral content when the shale has a great brittle mineral content [22]. This is because the rigid skeleton and compaction resistance of the brittle minerals effectively resisted the compaction of the underlying strata, the multiphase geological tectonic action, and the strong extrusion and deformation of the surrounding strata during the multiphase tectonic movement fracture modification, thus effectively protecting the pore structure of the brittle mineral edges [54]. Figure 11 shows the relationship between porosity and shale permeability impairment rate and stress sensitivity factor at initial effective stress, with the shale permeability impairment rate and stress sensitivity factor generally decreasing with increasing porosity. Although the permeability impairment rate and stress sensitivity factor for sample 1 are the smallest, the porosity is also the smallest. 


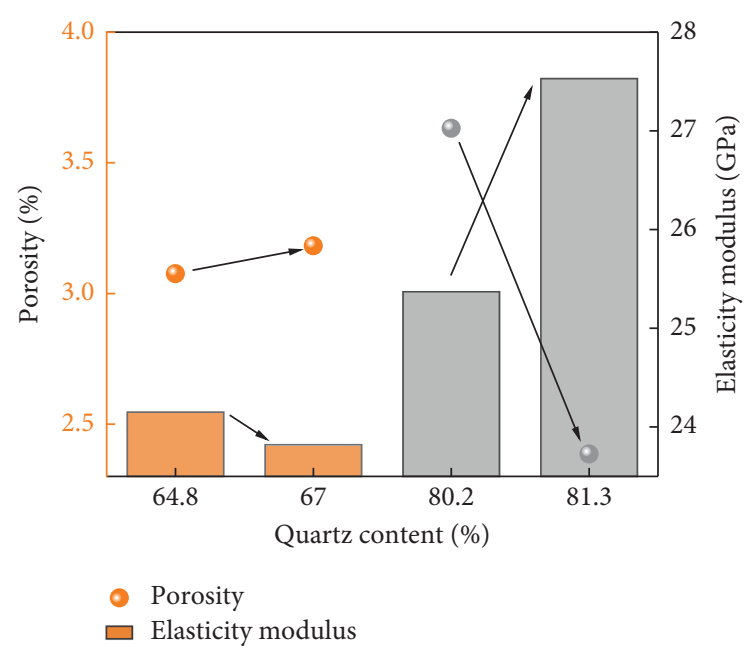

FIGURE 10: Modulus of elasticity corresponding to shales with different quartz contents.

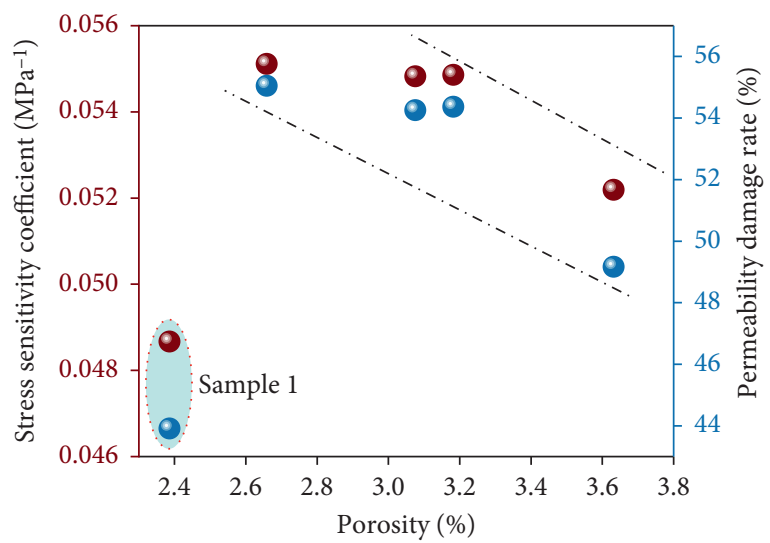

- Permeability damage rate

- Stress sensitivity coefficient

FIgURe 11: Porosity versus stress sensitivity coefficient and permeability damage rate of shale at initial effective stress.

The acidic fluids generated by the organic matrix in the shale during the evolution of hydrocarbon production dissolve brittle minerals and form a significant number of dissolved pores, especially carbonate minerals that are most susceptible to exfoliation and dissolution, such as calcite [20,21]. Nevertheless, analysis of the mineral composition of sample 1 shows that the shale lacks calcite mineral fill, which may be responsible for the minimal porosity of sample 1 . Nevertheless, sample 1 has a hard rigid skeleton and good compaction resistance due to its high brittle mineral content, resulting in a low shale permeability damage rate and stress sensitivity factor.

\subsubsection{Effect of Stress-Strain and Crack Extension on Stress} Sensitivity Coefficient in Shale. Stress-strain curves provide a good indication of the deformation and damage of the rock during compression, thus reflecting the nature of the rock and the factors that may influence it at each stage of deformation.
Figure 12 shows the stress-strain curves for deformation damage during compression of shale at different mineral components, which are similar to typical stress-strain curves, but with minor differences. (1) In the fracture compacting stage, the five samples show a similar upward concave pattern, indicating the existence of certain microcracks, micro-pores, and fillings in the samples, which show nonlinear characteristics during the stress loading process, the length of the process depends on the loading rate and the number of microcracks, micro-pores, and fillings. (2) After the sample is compacted, the deformation enters the elastic deformation stage, and the sample is transformed from a discontinuous medium to a seemingly continuous medium, the length of this stage depends on the hardness of the lithology. In Figures 12(a) and 12(e), linear characteristics appear after the fracture compacting stage until the rock sample breaks down, without yielding. This trend of the stress-strain curve is of the plastic-elastic type, indicating that not only is the fracture porosity developed in these two rock samples, but they are also very hard and dominated by elastic deformation. In terms of mineral content, these two rock samples have a large proportion of quartz, both exceeding $80 \%$, further indicating that quartz content has a critical influence on the mechanical characteristics of the shale. (3) In Figures 12(b) to 12(d), a small nonlinear yielding section is seen at the end of the curve because the quartz content in these three samples is much smaller than in the other two samples, which has relatively little influence on the mechanical properties of the shale. Second, the quartz content of the rock samples still represents a large proportion of the shale, so the stress-strain curve exhibits a slow plastic-elastic-plastic pattern. (4) Under continuous stress loading, the unit matrix inside the rock sample reaches its ultimate strength and the sample begins to deform, with microfractures, etc., sprouting and gradually forming penetrating damage surfaces and being split into mutually detached blocks, leading to destruction. In Figure 12, the curves of (a), (d), and (e) fall almost vertically after the bearing capacity reaches its peak, while the curves of (b) and (c) are at an angle, indicating that (a), (d), and (e) have obvious brittle damage characteristics, corresponding exactly to the three groups of rock samples with the highest quartz content. (5) From the damage characteristics of the rock samples at the peak stress, the damage of the rock samples in (b) and (c) is shear damage. During the stable rupture phase, the direction of growth of the tensile branch fractures sprouting in the rock sample gradually shifts towards the direction of maximum primary stress, that is, the axial direction. As the stress continues to load, the sample deforms into an unstable rupture phase, where a normal crushing zone perpendicular to the above fissures appears, causing damage to the rock bridge and continually weakening the rock in the locked section, leading to the destruction of the sample when all fissures turn parallel to the maximum principal stress. The fracture surface runs almost vertically through the entire sample, with few chunks falling and splashing out, suggesting that the axial main fracture surface controls the final destruction of the sample, as well as the relatively weak brittleness characteristics. In contrast, compared to (a), (d), and (e) of (b) and (c), there are many more fracture surfaces 


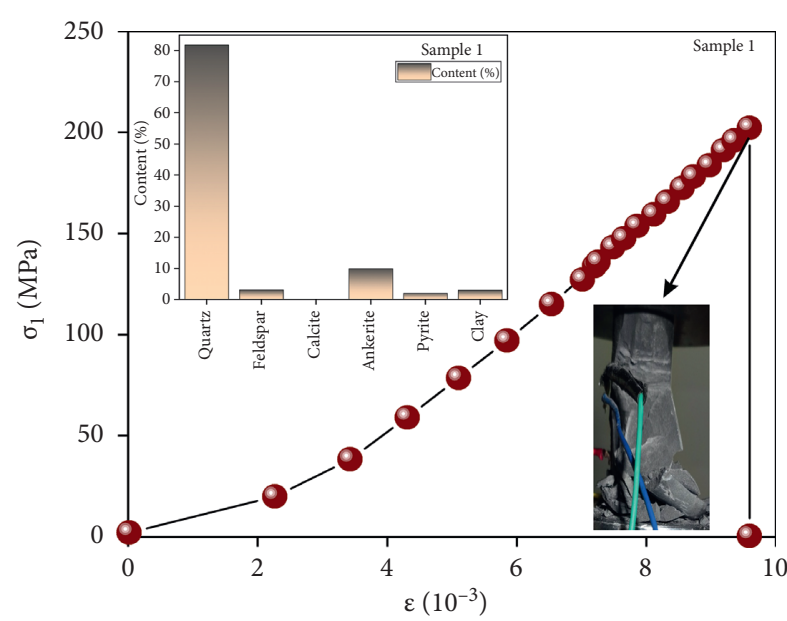

(a)

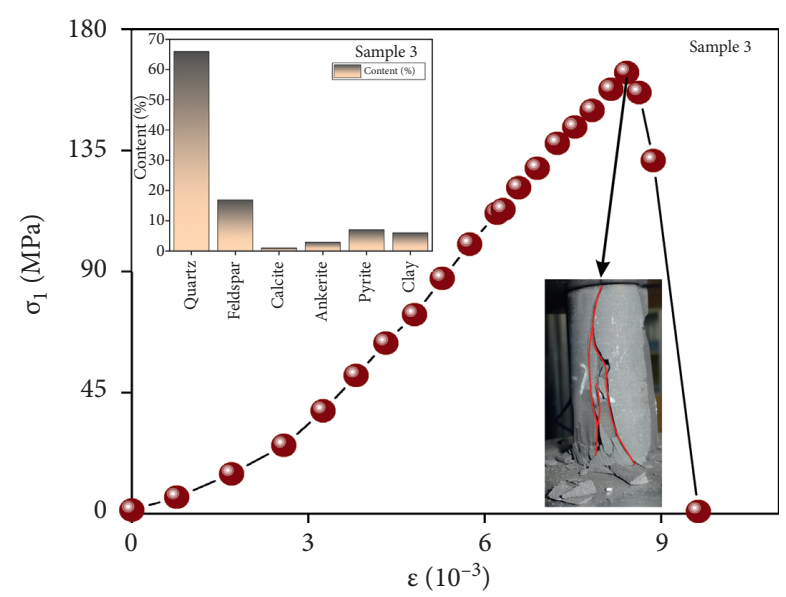

(c)

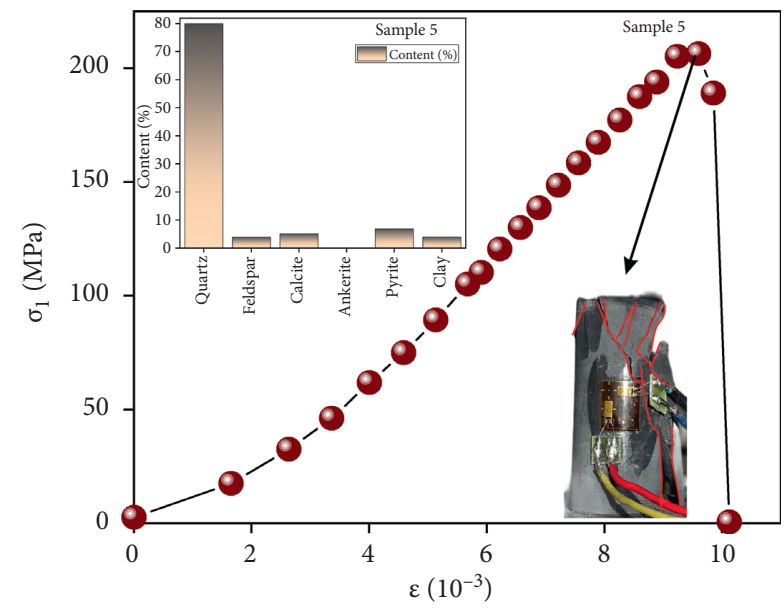

(e)

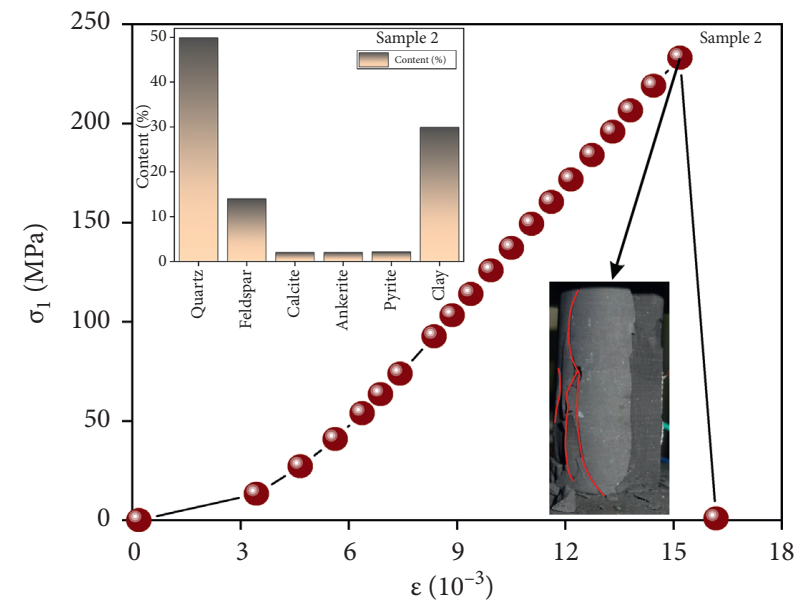

(b)

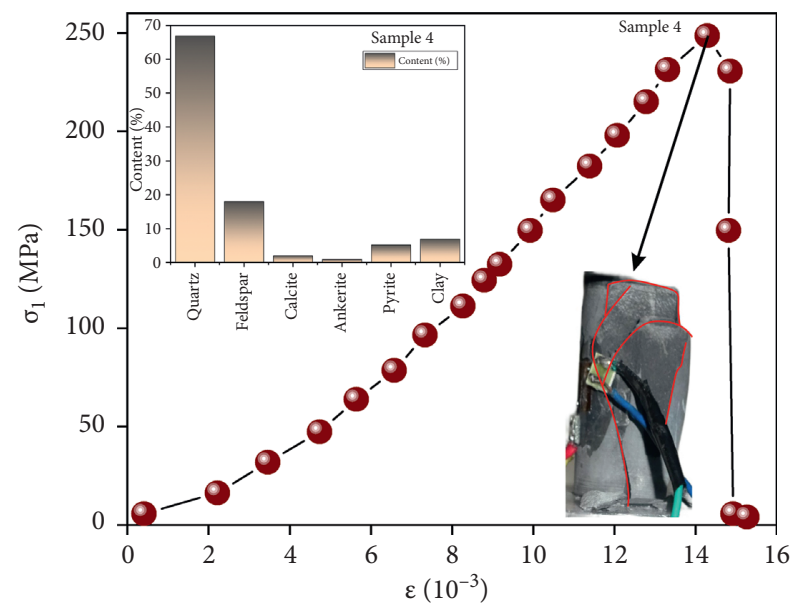

(d)

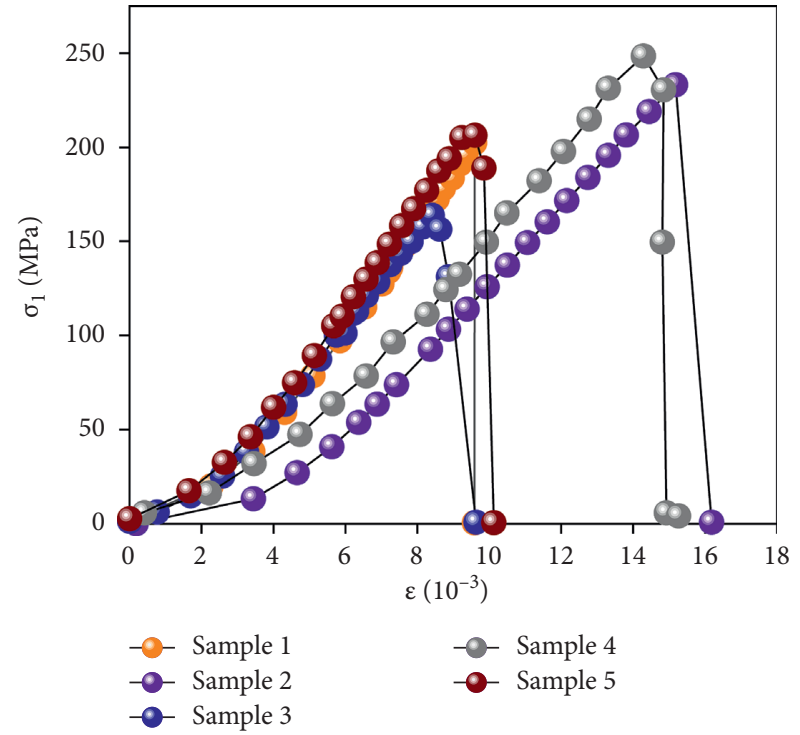

(f)

FIGURE 12: Stress-strain curves and damage characteristics of shales with different mineral components. 
leading to the final destruction of the rock sample, and the destruction is along the direction of the maximum primary stress, and the rock sample shows multiblock irregular destruction, especially (a) and (e) is the most significant, indicating good fracture development penetration.

In summary, when the sample has a great brittle mineral content and a small clay mineral content, the more brittle damage is likely to occur and the more cracks expand during compression, resulting in a lower stress sensitivity coefficient when elastic deformation is predominant. Conversely, when the sample has a low brittle mineral content and a high clay mineral content, the more pronounced the natural fractures and weak filler compression-density deformation during compression, the more cracks expand mainly along the weak zone and throughout the sample, resulting in a higher stress sensitivity coefficient.

\section{Conclusion}

This study focuses on the effect of mineral components in shale reservoirs of the Lower Cambrian Niutitang Formation in northern Guizhou on shale permeability, porosity, permeability impairment rate, stress sensitivity factor, and fracture extension, leading to the following conclusions:

(1) The permeability and porosity are negatively correlated with effective stress and clay mineral content, and positively correlated with detrital mineral content. Moreover, the permeability and porosity have a high fitting degree with effective stress, above $91 \%$. Whereas, the change of mineral component is not obvious for porosity.

(2) The permeability impairment rate and stress sensitivity factor are positively correlated and negatively correlated with effective stress, respectively. Simultaneously, the permeability impairment and stress sensitivity factor rate decrease with growing quartz content and modulus of elasticity, and increase with rising clay and feldspar mineral content. Nevertheless, the change of feldspar mineral content is not obvious for the permeability impairment rate and stress sensitivity factor.

(3) When the sample has a great brittle mineral content, the more brittle damage is likely to occur during compression with predominantly elastic deformation and the more crack extension, resulting in a lower stress sensitivity coefficient. Conversely, when the sample has a great clay mineral content, the more pronounced the natural fractures and weak filler compression-density deformation during compression, the more cracks expand mainly along the weak zone and throughout the sample, resulting in a higher stress sensitivity coefficient.

\section{Data Availability}

The data used to support the research are included within the article.

\section{Conflicts of Interest}

The authors declare that there are no conflicts of interest regarding the publication of this paper.

\section{Acknowledgments}

This study was supported by the National Natural Science Foundation of China (project no. 52104080) and Guizhou Science and Technology Fund (project no. [2021]401).

\section{References}

[1] M. Daniel, J. Ronald, and E. Tim, "A comparative study of the mississippian barnett shale, fort worth basin, and devonian marcellus shale, appalachian basin," AAPG Bulletin, vol. 91, no. 4, pp. 475-499, 2011.

[2] R. Wang, D. Gong, W. Ding et al., "Brittleness evaluation of the lower cambrian Niutitang shale in the upper yangtze region: a case study in the cen'gong block, Guizhou province," Earth Science Frontiers, vol. 23, no. 1, pp. 87-95, 2016.

[3] R. Wang, Z. Hu, L. Dong, B. Gao, and S. Yin, "Advancement and trends of shale gas reservoir characterization and evaluation," Oil and Gas Geology, vol. 42, no. 1, pp. 54-65, 2021.

[4] J. Yuan, D. Luo, and L. Feng, "A review of the technical and economic evaluation techniques for shale gas development," Applied Energy, vol. 148, pp. 49-65, 2015.

[5] M. Melikoglu, "Shale gas: analysis of its role in the global energy market," Renewable and Sustainable Energy Reviews, vol. 37, pp. 460-468, 2014.

[6] X. Jin, S. N. Shah, J.-C. Roegiers, and B. Zhang, "An integrated petrophysics and geomechanics approach for fracability evaluation in shale reservoirs," SPE Journal, vol. 20, no. 03, pp. 518-526, 2015.

[7] G. Kajari and M. Shankar, "Structural controls of fracture orientations, intensity, and connectivity, teton anticline, sawtooth range, montana," AAPG Bulletin, vol. 93, no. 8, pp. $995-1014,2009$.

[8] J. Liu, W. Ding, R. Wang et al., "Quartz types in shale and their effect on geomechanical properties: an example from the lower cambrian niutitang formation in the cen'gong block, South China," Applied Clay Science, vol. 163, pp. 100-107, 2018.

[9] Z. Jiang, Y. Song, X. Tang et al., "controlling factors of marine shale gas differential enrichment in southern China," Petroleum Exploration and Development, vol. 47, no. 3, pp. 661-673, 2020.

[10] D. J. K. Ross and R. Marc Bustin, "The importance of shale composition and pore structure upon gas storage potential of shale gas reservoirs," Marine and Petroleum Geology, vol. 26, no. 6, pp. 916-927, 2009.

[11] W. Sun, Y. Zuo, Z. Wu et al., "Fractal analysis of pores and the pore structure of the Lower Cambrian Niutitang shale in northern Guizhou province: investigations using NMR, SEM and image analyses," Marine and Petroleum Geology, vol. 99, pp. 416-428, 2019.

[12] H. Wang, Z. Qu, Y. Yin, J. Bai, and B. Yu, "Review of molecular simulation method for gas adsorption/desorption and diffusion in shale matrix," Journal of Thermal Science, vol. 28, no. 1, pp. 1-16, 2019.

[13] R. Yang, S. He, J. Yi, and Q. Hu, "Nano-scale pore structure and fractal dimension of organic-rich Wufeng-Longmaxi shale from Jiaoshiba area, Sichuan Basin: investigations using 
FE-SEM, gas adsorption and helium pycnometry," Marine and Petroleum Geology, vol. 70, pp. 27-45, 2016.

[14] Z. Zhai, X. Wang, X. Jin, L. Sun, J. Li, and D. Cao, "Adsorption and diffusion of shale gas reservoirs in modeled clay minerals at different geological depths," Energy and Fuels, vol. 28, no. 12, pp. 7467-7473, 2014.

[15] L. Zeng, H. Wang, L. Gong, and B. Liu, "Impacts of the tectonic stress field on natural gas migration and accumulation: a case study of the Kuqa depression in the tarim basin, China," Marine and Petroleum Geology, vol. 27, no. 7, pp. 1616-1627, 2010.

[16] Z.-Q. Li, X.-L. Li, J.-B. Yu et al., "Influence of existing natural fractures and beddings on the formation of fracture network during hydraulic fracturing based on the extended finite element method," Geomechanics and Geophysics for Geo-Energy and Geo-Resources, vol. 6, no. 4, p. 58, 2020.

[17] X. Wang, W. Ding, L. Cui et al., "The developmental characteristics of natural fractures and their significance for reservoirs in the Cambrian Niutitang marine shale of the Sangzhi block, southern China," Journal of Petroleum Science and Engineering, vol. 165, pp. 831-841, 2018.

[18] P. Guo, L. Yao, and D. Ren, "Simulation of three-dimensional tectonic stress fields and quantitative prediction of tectonic fracture within the damintun depression, Liaohe Basin, Northeast China," Journal of Structural Geology, vol. 86, pp. 211-223, 2016.

[19] T. Hu, X. Pang, F. Jiang et al., "Key factors controlling shale oil enrichment in saline lacustrine rift basin: implications from two shale oil wells in Dongpu Depression, Bohai Bay Basin," Petroleum Science, vol. 18, no. 3, pp. 687-711, 2021.

[20] W. Sun, Y. Zuo, S. Wang et al., "Pore structures of shale cores in different tectonic locations in the complex tectonic region: a case study of the Niutitang Formation in Northern Guizhou, Southwest China," Journal of Natural Gas Science and Engineering, vol. 80, Article ID 103398, 2020.

[21] W. Sun, Y. Zuo, Z. Wu et al., "Pore characteristics and evolution mechanism of shale in a complex tectonic area: case study of the lower cambrian Niutitang formation in northern Guizhou, southwest China," Journal of Petroleum Science and Engineering, vol. 193, Article ID 107373, 2020.

[22] W. Sun, Y. Zuo, Z. Wu, H. Liu, and X. Luo, “The distribution characteristics of brittle minerals in the lower cambrian niutitang formation in Northern Guizhou," Journal of Natural Gas Science and Engineering, vol. 86, Article ID 103752, 2020.

[23] A. Li, W. Ding, K. Jiu, Z. Wang, R. Wang, and J. He, "Investigation of the pore structures and fractal characteristics of marine shale reservoirs using NMR experiments and image analyses: a case study of the lower cambrian niutitang formation in Northern Guizhou Province, South China," Marine and Petroleum Geology, vol. 89, pp. 530-540, 2018.

[24] J. Liu, W. Ding, R. Wang, S. Yin, H. Yang, and Y. Gu, "Simulation of paleotectonic stress fields and quantitative prediction of multi-period fractures in shale reservoirs: a case study of the Niutitang Formation in the lower cambrian in the Cen'gong block, South China," Marine and Petroleum Geology, vol. 84, pp. 289-310, 2017.

[25] K. Jiu, W. Ding, Y. Li, J. Zhang, and W. Zeng, "Structural features in Northern Guizhou area and reservoir of lower Cambrian shale gas," Natural Gas Geoscience, vol. 23, no. 4, pp. 797-803, 2012.

[26] Z. Wu, Y. Zuo, S. Wang et al., "Numerical simulation and fractal analysis of mesoscopic scale failure in shale using digital images," Journal of Petroleum Science and Engineering, vol. 145, pp. 592-599, 2016.
[27] J. He, W. Ding, Z. Jiang, A. Li, R. Wang, and Y. Sun, "Logging identification and characteristic analysis of the lacustrine organic-rich shale lithofacies: a case study from the Es $3 \mathrm{~L}$ shale in the Jiyang Depression, Bohai Bay Basin, Eastern China," Journal of Petroleum Science and Engineering, vol. 145, pp. 238-255, 2016.

[28] Z. Wu, Y. Zuo, S. Wang et al., "Numerical study of multiperiod palaeotectonic stress fields in lower cambrian shale reservoirs and the prediction of fractures distribution: a case study of the niutitang formation in Feng'gang No. 3 block, South China," Marine and Petroleum Geology, vol. 80, pp. 369-381, 2017.

[29] S. Yin, W. Ding, W. Zhou et al., "Logging assessment of tight clastic rock reservoir fractures via the extraction of effective pore aspect ratios: a case study of lower Permian strata in the Southern Qinshui Basin of Eastern China," Journal of Natural Gas Science and Engineering, vol. 36, pp. 597-616, 2016.

[30] X. Wang, R. Wang, W. Ding et al., "Development characteristics and dominant factors of fractures and their significance for shale reservoirs: a case study from $€ 1$ b2 in the Cen'gong block, Southern China," Journal of Petroleum Science and Engineering, vol. 159, pp. 988-999, 2017.

[31] R. Wang, W. Ding, Y. Zhang et al., "Analysis of developmental characteristics and dominant factors of fractures in Lower Cambrian marine shale reservoirs: a case study of Niutitang formation in Cen'gong block, southern China," Journal of Petroleum Science and Engineering, vol. 138, pp. 31-49, 2016.

[32] T. Hu, X. Pang, F. Jiang et al., "Movable oil content evaluation of lacustrine organic-rich shales: methods and a novel quantitative evaluation model," Earth-Science Reviews, vol. 214, no. 1, Article ID 103545, 2021.

[33] T. Hu, X. Pang, S. Jiang et al., "Oil content evaluation of lacustrine organic-rich shale with strong heterogeneity: a case study of the Middle Permian Lucaogou Formation in Jimusaer Sag, Junggar Basin, NW China," Fuel, vol. 221, pp. 196-205, 2018.

[34] W. Ding, D. Zhu, J. Cai, M. Gong, and F. Chen, "Analysis of the developmental characteristics and major regulating factors of fractures in marine-continental transitional shale-gas reservoirs: a case study of the Carboniferous-Permian strata in the southeastern Ordos Basin, central China," Marine and Petroleum Geology, vol. 45, pp. 121-133, 2013.

[35] Z. Zhao, X. Li, J. He, T. Mao, G. Li, and B. Zheng, "Investigation of fracture propagation characteristics caused by hydraulic fracturing in naturally fractured continental shale," Journal of Natural Gas Science and Engineering, vol. 53, pp. 276-283, 2018.

[36] Z. Li, L. Li, M. Li et al., "A numerical investigation on the effects of rock brittleness on the hydraulic fractures in the shale reservoir," Journal of Natural Gas Science and Engineering, vol. 50, pp. 22-32, 2017.

[37] Y. Lou, Z. Wu, W. Sun et al., "Study on failure models and fractal characteristics of shale under seepage-stress coupling," Energy Science \& Engineering, vol. 8, pp. 1-16, 2020.

[38] J. Zhang, Z. Jiang, S. Wang, R. Wang, Y. Zhang, and W. Du, "Bedding-parallel calcite veins as a proxy for shale reservoir quality," Marine and Petroleum Geology, vol. 127, no. Suppl, Article ID 104975, 2021.

[39] Y. Zou, X. Ma, S. Zhang, T. Zhou, and H. Li, "Numerical investigation into the influence of bedding plane on hydraulic fracture network propagation in shale formations," Rock Mechanics and Rock Engineering, vol. 49, pp. 3597-3614, 2016.

[40] Y. Zou, S. Zhang, X. Ma, T. Zhou, and B. Zeng, "Numerical investigation of hydraulic fracture network propagation in 
naturally fractured shale formations," Journal of Structural Geology, vol. 84, pp. 1-13, 2016.

[41] Z. Geng, M. Chen, Y. Jin et al., "Experimental study of brittleness anisotropy of shale in triaxial compression," Journal of Natural Gas Science and Engineering, vol. 36, pp. 510-518, 2016.

[42] S. Yin, D. Lv, L. Jin, and W. Ding, "Experimental analysis and application of the effect of stress on continental shale reservoir brittleness," Journal of Geophysics and Engineering, vol. 15, no. 2, pp. 1-24, 2018.

[43] D. Zhang, P. G. Ranjith, and M. S. A. Perera, "The brittleness indices used in rock mechanics and their application in shale hydraulic fracturing: a review," Journal of Petroleum Science and Engineering, vol. 143, pp. 158-170, 2016.

[44] Z. Xi, S. Tang, J. Li, Z. Zhang, and H. Xiao, "Pore characterization and the controls of organic matter and quartz on pore structure: case study of the Niutitang Formation of northern Guizhou Province, South China," Journal of Natural Gas Science and Engineering, vol. 61, pp. 18-31, 2019.

[45] Z. Wu, Y. Zuo, S. Wang, J. Sunwen, and L. Liu, "Experimental study on the stress sensitivity and influence factors of shale under varying stress," Shock and Vibration, vol. 2018, no. 12, 9 pages, Article ID 3616942, 2018.

[46] Y.-S. Yuan, Z.-J. Jin, Y. Zhou, J.-X. Liu, S.-J. Li, and Q.-Y. Liu, "Burial depth interval of the shale brittle-ductile transition zone and its implications in shale gas exploration and production," Petroleum Science, vol. 14, no. 4, pp. 637-647, 2017.

[47] Z. Meng and Q. Hou, "Experimental research on stress sensitivity of coal reservoir and its influencing factors," Journal of China Coal Society, vol. 37, no. 3, pp. 430-437, 2012.

[48] Z. Meng and G. Li, "Experimental research on the permeability of high-rank coal under a varying stress and its influencing factors," Engineering Geology, vol. 162, pp. 108117, 2013.

[49] R. M. Holt, E. Fjær, J. F. Stenebråten, and O.-M. Nes, "Brittleness of shales: relevance to borehole collapse and hydraulic fracturing," Journal of Petroleum Science and Engineering, vol. 131, no. 131, pp. 200-209, 2015.

[50] C. Li, "A theoretical formula of stress sensitivity index with compressibility of rock," Lithologic Reservoirs, vol. 19, no. 4, pp. 95-98, 2007.

[51] R. M. Slatt and N. R. O’Brien, "Pore types in the Barnett and Woodford gas shales: contribution to understanding gas storage and migration pathways in fine-grained rocks," $A A P G$ Bulletin, vol. 95, no. 12, pp. 2017-2030, 2011.

[52] R. G. Loucks, R. M. Reed, S. C. Ruppel, and U. Hammes, "Spectrum of pore types and networks in mudrocks and a descriptive classification for matrix-related mudrock pores," AAPG Bulletin, vol. 96, no. 6, pp. 1071-1098, 2012.

[53] H. S. Rabbani, B. Zhao, R. Juanes, and N. Shokri, "Pore geometry control of apparent wetting in porous media," Scientific Reports, vol. 8, no. 1, p. 15729, 2018.

[54] F. Chen, X. Ding, and S. Lu, "Organic porosity evaluation of lower cambrian Niutitang shale in qiannan depression, China," Petroleum Science and Technology, vol. 34, no. 11-12, pp. 1083-1090, 2016. 